\title{
Temperature- and concentration-dependence of kainate-induced y oscillation in rat hippocampal slices under submerged condition
}

\author{
Cheng-biao $\mathrm{LU}^{1, *}$, Zhi-hua WANG ${ }^{1}$, Yan-hong ZHOU², Martin VREUGDENHIL ${ }^{3}$ \\ ${ }^{1}$ Department of Automation, Institute of Electrical Engineering, Yanshan University, Qinhuangdao 066004, China; ${ }^{2}$ Department of \\ Computer, Institute of Mathematics and Information Technology, Hebei Normal University of Science and Technology, Qinhuangdao \\ 066004, China; ${ }^{3}$ Department of Neurophysiology, University of Birmingham, Birmingham, West Midlands, United Kingdom
}

\begin{abstract}
Aim: Fast neuronal network oscillation at the $\mathrm{y}$ frequency band ( $\mathrm{y}$ oscillation: $30-80 \mathrm{~Hz}$ ) has been studied extensively in hippocampal slices under interface recording condition. The aim of this study is to establish a method for recording $\mathrm{y}$ oscillation in submerged hippocampal slices that allows simultaneously monitoring $\mathrm{y}$ oscillation and the oscillation-related intracellular events, such as intracellular $\mathrm{Ca}^{2+}$ concentration or mitochondrial membrane potentials.

Methods: Horizontal hippocampal slices (thickness: $300 \mu \mathrm{m}$ ) of adult rats were prepared and placed in a submerged or an interface chamber. Extracellular field recordings were made in the CA3c pyramidal layer of the slices. Kainate, an AMPA/kainate receptor agonist, was applied via perfusion. Data analysis was performed off-line.

Results: Addition of kainate (25-1000 nmol/L) induced y oscillation in both the submerged and interface slices. Kainate increased the $y$ power in a concentration-dependent manner, but the duration of steady state oscillation was reduced at higher concentrations of kainate. Long-lasting y oscillation was maintained at the concentrations of $100-300 \mathrm{nmol} / \mathrm{L}$. Under submerged condition, y oscillation was temperature-dependent, with the maximum power achieved at $29^{\circ} \mathrm{C}$. The induction of $\mathrm{y}$ oscillation under submerged condition also required a fast rate of perfusion $(5-7 \mathrm{~mL} / \mathrm{min})$ and showed a fast dynamic during development and after the washout. Conclusion: The kainite-induced y oscillation recorded in submerged rat hippocampal slices is useful for studying the intracellular events related to neuronal network activities and may represent a model to reveal the mechanisms underlying the normal neuronal synchronizations and diseased conditions.
\end{abstract}

Keywords: y oscillation; neuronal network; hippocampus; kainite; submerged slice

Acta Pharmacologica Sinica (2012) 33: 214-220; doi: 10.1038/aps.2011.159; published online 23 Jan 2012

\section{Introduction}

Neuronal network oscillations at the gamma frequency band ( $\gamma$ oscillations, 30-80 Hz) generated in the cortex play an important role in learning and memory ${ }^{[1,2]}$. These oscillations provide a timing mechanism for controlling information processing $^{[1,3]}$. Impairments of $\gamma$ oscillations have been associated with Alzheimer's disease ${ }^{[4]}$ and normal aging. Both in vivo ${ }^{[5]}$ and in vitro ${ }^{[6,7]}$ studies have suggested that intrahippocampally generated $\gamma$ activity emerges from the rhythmic activity of interneurons that receive converging inputs from pyramidal neurons and control their firing through divergent outputs. The similarity in the timing of the unit discharges to the field potentials observed both in vivo and in vitro have validated the

\footnotetext{
* To whom correspondence should be addressed.

E-mail cblu@ysu.edu.cn

Received 2011-06-29 Accepted 2011-10-26
}

in vitro $\gamma$ models.

In vitro models of hippocampal $\gamma$ oscillations rely on a depolarizing drive provided by specific agonists for the metabotropic glutamate, muscarinic acetylcholine or kainate receptors. Most in vitro oscillations have been shown to be accurate experimental models for the study of in vivo $\gamma$ oscillations ${ }^{[5,8,9]}$. Although in vitro $y$ oscillations are primarily studied under interface conditions and have provided valuable information for an understanding of the mechanisms of oscillatory activities, the limitation of this model is its inability to detect intracellular events, such as intracellular calcium concentrations or mitochondrial functions in individual neurons, which are critical for neuronal network oscillations ${ }^{[10]}$. To study intracellular events related to $\gamma$ oscillations, an in vitro $\gamma$ recording under submerged conditions is essential. Previous studies reported the difficulty of inducing and maintaining $\gamma$ oscillations under submerged conditions ${ }^{[7,11,12]}$. Here, we aim to develop 
a method for recording persistent $\gamma$ oscillations under submerged conditions that is capable of simultaneously monitoring y oscillations and oscillation-related intracellular events.

By optimizing the experimental conditions, we established a method in which persistent $\gamma$ oscillations can be reliably induced in the hippocampal CA3 area and that provides a superior model for the study of cellular mechanisms underlying $\gamma$ oscillations.

\section{Materials and methods Animal model}

All procedures were carried out under UK home office license and in accordance with the regulation of the UK Animals Act, 1998 and associated guidance. All efforts were made to minimize animal suffering, reduce the number of animals used, and utilize alternatives to in vivo techniques, if available.

Young adult rats (3-4 months) were anesthetized by intraperitoneal injection of a ketamine $(76 \mathrm{mg} / \mathrm{kg}) /$ medetomidine $(1 \mathrm{mg} / \mathrm{kg})$ mixture and then sacrificed by cervical dislocation. The brain was quickly removed and immersed in an ice-cold sucrose-ACSF solution saturated with $95 \% \mathrm{O}_{2} / 5 \% \mathrm{CO}_{2}$ and contained the following (in mmol/L): 189 sucrose, $2.5 \mathrm{KCl}, 0.5$ $\mathrm{CaCl}_{2}, 10 \mathrm{MgCl}_{2}, 26 \mathrm{NaHCO}_{3}, 1.25 \mathrm{NaH}_{2} \mathrm{PO}_{4}$, and 10 glucose. Horizontal hippocampal slices were cut into $300-\mu \mathrm{m}$ sections using an Integraslice (Campden Instruments, UK). The slices were then stored in an interface chamber at room temperature $\left(22-23^{\circ} \mathrm{C}\right)$ bubbled with a mixture of $95 \% \mathrm{O}_{2} / 5 \% \mathrm{CO}_{2}$.

\section{Test procedure}

A slice was placed in an interface or submerged chamber and allowed to equilibrate for an hour in artificial ACSF before recording. The bath temperature was measured using a digital temperature meter (Hanna Instruments, Ann Arbor, Michigan, USA). Temperature alterations in the recording chambers were achieved by either increasing or decreasing the water temperature in the water bath. For interface slices, the temperature and perfusion rate were maintained at $31-32^{\circ} \mathrm{C}$ and $2-3 \mathrm{~mL} / \mathrm{min}$, respectively. The optimal conditions for $\mathrm{Y}$ activity in the submerged slices were $28-29^{\circ} \mathrm{C}$ and $5-7 \mathrm{~mL} /$ min for temperature and perfusion rate, respectively. The composition of ACSF was (in mmol/L) $125 \mathrm{NaCl}, 26 \mathrm{NaHCO}_{3}$, $3 \mathrm{KCl}, 2 \mathrm{CaCl}_{2}, 1.25 \mathrm{NaH}_{2} \mathrm{PO}_{4}, 1 \mathrm{MgCl}_{2}$, and $10 \mathrm{D}$-glucose, and its $\mathrm{pH}$ was equilibrated with a mixture of $95 \% \mathrm{O}_{2} / 5 \% \mathrm{CO}_{2}$ at $\mathrm{pH}$ 7.4. The slices were visualized with a stereo microscope (Leica MZ8, Micro Instruments, Oxford, UK). Electrodes (2 to $4 \mathrm{M} \Omega$ ) were pulled from borosilicate glass capillaries of 1.2 mm OD $\times 0.69$ mm ID (Harvard Apparatus, Edenbridge, Kent, UK) using a P-97 horizontal micropipette puller (Sutter Instrument Company, Novato, CA, USA) and filled with ACSF.

The electrodes were placed in the stratum radiatum (SR) of area CA3 in the hippocampus for the interface chamber, as the $\mathrm{SR}$ appears to be most reliable location to induce $\gamma$ oscillation. For the same reason, the stratum pyramidale (SP) of the CA3 is used for the submerged recording of KA-induced $\gamma$ oscillation. The coherence of the $\gamma$ oscillations was studied by placing one electrode in CA3C and moving a second electrode in $\sim 200-\mu \mathrm{m}$ steps along the cell layer of the Ammon horn. After recording a baseline for approximately 5-10 $\mathrm{min}, \gamma$ oscillations were induced by adding various concentrations of KA.

The extracellular microelectrodes were connected to an AC-DC amplifier (Neurolog System, Digitimer, Welwyngarden City, UK). The signals were sampled at $5 \mathrm{kHz}$ using a CED 1401 interface and low-pass filtered at $2.5 \mathrm{kHz}$ using a Neurolog NL-125 filter unit (Digitimer). For the continuous recording in submerged slices, signals were sampled at $1 \mathrm{kHz}$ and filtered at $0.5 \mathrm{kHz}$. A Humbug noise-eliminator (Digitimer) was used to remove line noise. Signal 2 and Spike 2 were used for data acquisition. Data analysis was performed off-line using Spike 2 and Signal 2 (Cambridge electronic design [CED], Cambridge, UK), SigmaStat (SPSS Inc, USA) and Microsoft Excel software.

The power of network oscillations was measured using fast Fourier transformation (FFT) over 20-100 s of data, which quantifies the proportional power of each wavelength within the data section. The summated power value of the $\gamma$ oscillation is a summation of powers ranging between $20-60 \mathrm{~Hz}$ in vitro, first adopted by Fisahn et al ${ }^{[6]}$.

\section{Statistical analysis}

The data are expressed as the mean and standard error of the mean, with $n$ indicating the number of slices.

\section{Results}

\section{KA-induced $y$ oscillations}

Extracellular field recordings were made in the hippocampal CA3c pyramidal layer in both submerged and interface slices. KA-induced $\gamma$ oscillations developed in a time-dependent manner. At $100 \mathrm{nmol} / \mathrm{L}, \mathrm{KA}$-induced oscillations required 2-10 min to reach the peak $(n=8)$ for submerged slices and 30-70 $\min (n=7)$ for interface recordings. The oscillations lasted longer than $30 \mathrm{~min}$ and for a few hours for the submerged and interface slice recordings, respectively. After washout of KA, the oscillations generally required 20-30 $\mathrm{min}$ to recover in submerged recordings but could take hours to recover in the interface recordings.

Power spectra analysis indicated that the dominant oscillation frequency in the submerged and interface recordings were approximately 25 and $40 \mathrm{~Hz}$, respectively (Figure 1). A frequency of $25 \mathrm{~Hz}$ was at the lower range of $\gamma$ oscillations $(20-59 \mathrm{~Hz})$. This frequency was associated with the lower temperature in the recording chamber in the submerged slices $\left(29^{\circ} \mathrm{C}\right)$.

\section{Temperature dependence}

The optimum temperature for KA-induced $\gamma$ oscillations under submerged conditions was determined, and the temperature affected $\gamma$ oscillations in the submerged slices. Increasing the temperature from $23-36^{\circ} \mathrm{C}$ altered the frequency and power of the oscillation. Representative traces of oscillatory activity at 25 and $29^{\circ} \mathrm{C}$ are shown in Figure 2A. The frequency of oscillations increased from 18 to $25 \mathrm{~Hz}$ as the temperature increased from 25 to $29^{\circ} \mathrm{C}$ (Figure 2B). The temperature-dependence 
A

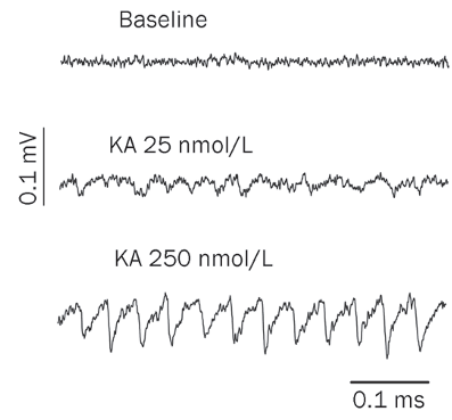

B
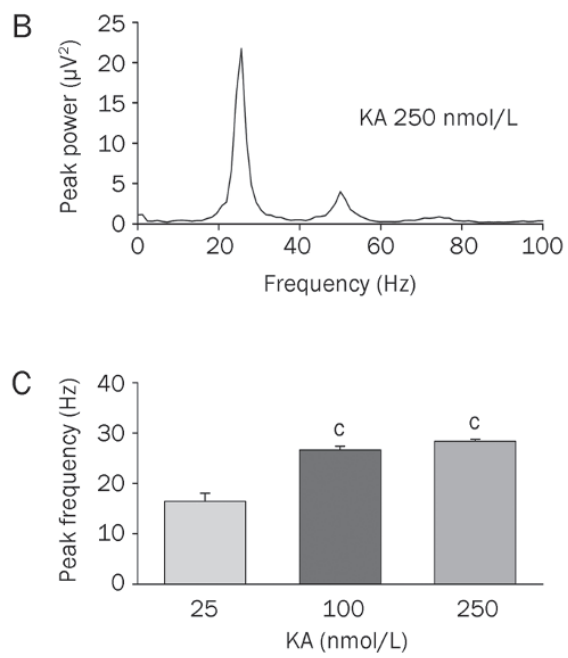

Figure 1. Kainate-induced y oscillations. A) Example traces of oscillatory activities induced by various concentrations of KA in submerged slices. B) Power spectra from oscillations induced by $\mathrm{KA}(250 \mathrm{nmol} / \mathrm{L})$ show that the peak frequency for submerged slice is $25 \mathrm{~Hz}$. C) Bar graphs show the average peak frequency of oscillatory activity induced by various concentration of KA in submerged slices. ${ }^{\circ} P<0.01$, compared with $25 \mathrm{nmol} / \mathrm{L} \mathrm{KA}$ group, ANOVA.

of oscillation frequency over a range of temperatures from $23-33^{\circ} \mathrm{C}$ is depicted in Figure $2 \mathrm{C}$. Based on the linear fit, the calculated change in response to a $1^{\circ} \mathrm{C}$ increase in temperature corresponds to a $2.3 \pm 0.4 \mathrm{~Hz}$ increase in the oscillation frequency $(n=7)$. Although the oscillation frequency was positively correlated with temperature over a range of $23-33^{\circ} \mathrm{C}, \gamma$ power was only correlated with temperature within a limited temperature range. Increasing the temperature increased the $Y$ power (Figure 2C). The highest $Y$ power was achieved at $27-29{ }^{\circ} \mathrm{C}$. As the temperature was further increased, the $\gamma$ power was reduced (Figure 2C).

\section{Concentration dependence}

$\mathrm{KA}$ increased the $\mathrm{Y}$ power (Figure 3 ) in both interface and submerged slices in a concentration-dependent manner. At $25 \mathrm{nmol} / \mathrm{L} \mathrm{KA}$, the average $\mathrm{\gamma}$ power was $303 \pm 154 \mu \mathrm{V}^{2} \quad(n=7)$ and $26 \pm 13 \mu \mathrm{V}^{2}(n=8)$ for the interface and submerged slices, respectively. At $100 \mathrm{nmol} / \mathrm{L} \mathrm{KA}$, the $\mathrm{y}$ power increased to $2308 \pm 691 \mu \mathrm{V}^{2}(n=7)$ and $195 \pm 91 \mu \mathrm{V}^{2}(n=8)$ for the interface and submerged slices, respectively. At $250 \mathrm{nmol} / \mathrm{L} \mathrm{KA}$, the

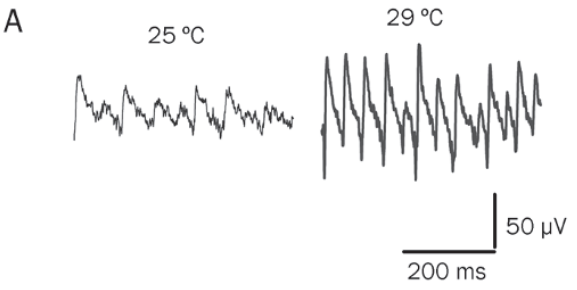

B
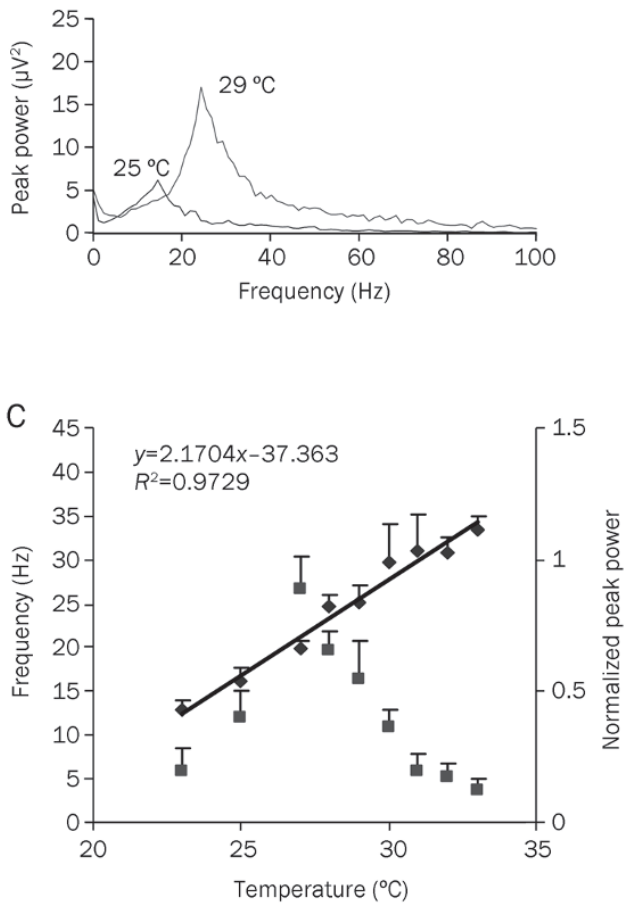

Figure 2. Oscillatory activity is temperature-dependent. A) Examples of KA-induced field potentials in a submerged slice at $25^{\circ} \mathrm{C}$ and $29^{\circ} \mathrm{C}$. Recordings were made in SP of CA3. B) Power spectra at different temperatures, corresponding to the field potentials in A. C) Plots of oscillation frequency (diamond) and the peak power of oscillations (square) as a function of temperature for the submerged slices.

$Y$ power further increased for both interface and submerged conditions (Figure 3C, 3D). Increasing the KA concentration also accelerated the development of $\gamma$ oscillations, as represented by a reduction in the time to reach peak power. For the interface slices, the time to peak $\gamma$ power was $110 \pm 16.4$ $\mathrm{min}, 103 \pm 4.6 \mathrm{~min}$, and $27 \pm 4.9 \mathrm{~min}$ for $25 \mathrm{nmol} / \mathrm{L}, 100 \mathrm{nmol} / \mathrm{L}$, and $250 \mathrm{nmol} / \mathrm{L} \mathrm{KA}$, respectively. For the submerged slices, the time to peak $Y$ power was $68 \pm 7.9 \mathrm{~min}, 12.2 \pm 2.2 \mathrm{~min}$, and $4.7 \pm 1.97 \mathrm{~min}$ for $25 \mathrm{nmol} / \mathrm{L}, 100 \mathrm{nmol} / \mathrm{L}$, and $250 \mathrm{nmol} / \mathrm{L} \mathrm{KA}$, respectively.

Although the maximum $y$ powers under both conditions increased by KA in a concentration-dependent manner, $Y$ maintenance appeared to be reduced at higher KA concentrations. At $25 \mathrm{nmol} / \mathrm{L} \mathrm{KA}$, the steady state of $\mathrm{y}$ oscillations lasted for a few hours in the interface slices $(n=7)$ and longer than $50 \mathrm{~min}$ in the submerged slices $(n=8)$, but at $250 \mathrm{nmol} / \mathrm{L}$, the steady state of $y$ oscillations was maintained for less than an hour for the interface slices $(P<0.01$, compared with that of 
the $25 \mathrm{nmol} / \mathrm{L} \mathrm{KA}$ interface slice group) and less than $30 \mathrm{~min}$ for submerged slices $(P<0.01$, compared with that of the 25 nmol/L KA submerged slice group). In 5 submerged slices tested, high concentrations of KA $(1.5 \mu \mathrm{mol} / \mathrm{L})$ induced rapidly developing (2-3 min), strong $Y$ oscillations, which lasted for only a couple of minutes (Figure 3F).

\section{Area and layer specificity}

In interface chamber recordings, the strongest $\gamma$ oscillations were usually recorded in the CA3c area (closest to the hilus), followed by $\mathrm{CA} 3 \mathrm{~b}$ and $\mathrm{CA} 3 \mathrm{a}^{[13]}$. Representative results of $\mathrm{\gamma}$ oscillations recorded from these three areas (CA3a, CA3b, and $C A 3 c$ ) from an interface slice are shown in Figure 4A-4D. These recordings were repeated in the submerged slices, and similar results were obtained (data not shown). Therefore, $\gamma$ oscillations were routinely recorded in the submerged slices in the CA3c area. Oscillatory activity can be recorded in the somatic (stratum pyramidale, SP) and apical dendritic layer (stratum radiatum, SR), with positive population synaptic potentials in the somatic region (SP) and negative potentials in the SR (Figure 4E). In the interface slices, the strongest $\gamma$ oscillations were recorded in the SR, followed by the SP and stratum oriens (SO). In the submerged slices, the $\gamma$ power was highest in the SP, followed by the SR and SO (Figure 4F).

\section{Oscillations are mediated by both excitatory and inhibitory synapses}

$\mathrm{KA}$-induced $\gamma$ oscillations require KA receptor activation as well as excitatory glutamatergic and inhibitory GABAergic neurotransmission. The effects of the AMPA/KA receptor blocker, NBQX, and the $\mathrm{GABA}_{\mathrm{A}}$ receptor blocker, GABAzine, were tested on KA-induced $(100 \mathrm{nmol} / \mathrm{L})$ y oscillations. On average, the $\gamma$ power was reduced to $0.9 \% \pm 0.3 \%$ that of the control $(100 \%)$ by NBQX $(n=4, P<0.01)$ and to $3.1 \% \pm 2.1 \%$ of the control by GABAzine $(n=4, P<0.05)$. After $20 \mathrm{~min}$ washout of GABAzine, the $\gamma$ oscillations partially recovered $(47 \% \pm 20 \%$ of control, $n=4)$, but no significant recovery was observed after NBQX washout $(1.2 \% \pm 0.2 \%$ of control). TTX $(1 \mu \mathrm{mol} / \mathrm{L})$ reduced the $\gamma$ powers to $24.2 \% \pm 3.8 \%(P<0.05, n=4)$ that of the control at $20 \mathrm{~min}$ of application, which did not recover at washout $(0.54 \% \pm 0.26 \%$ of the control, data not shown).
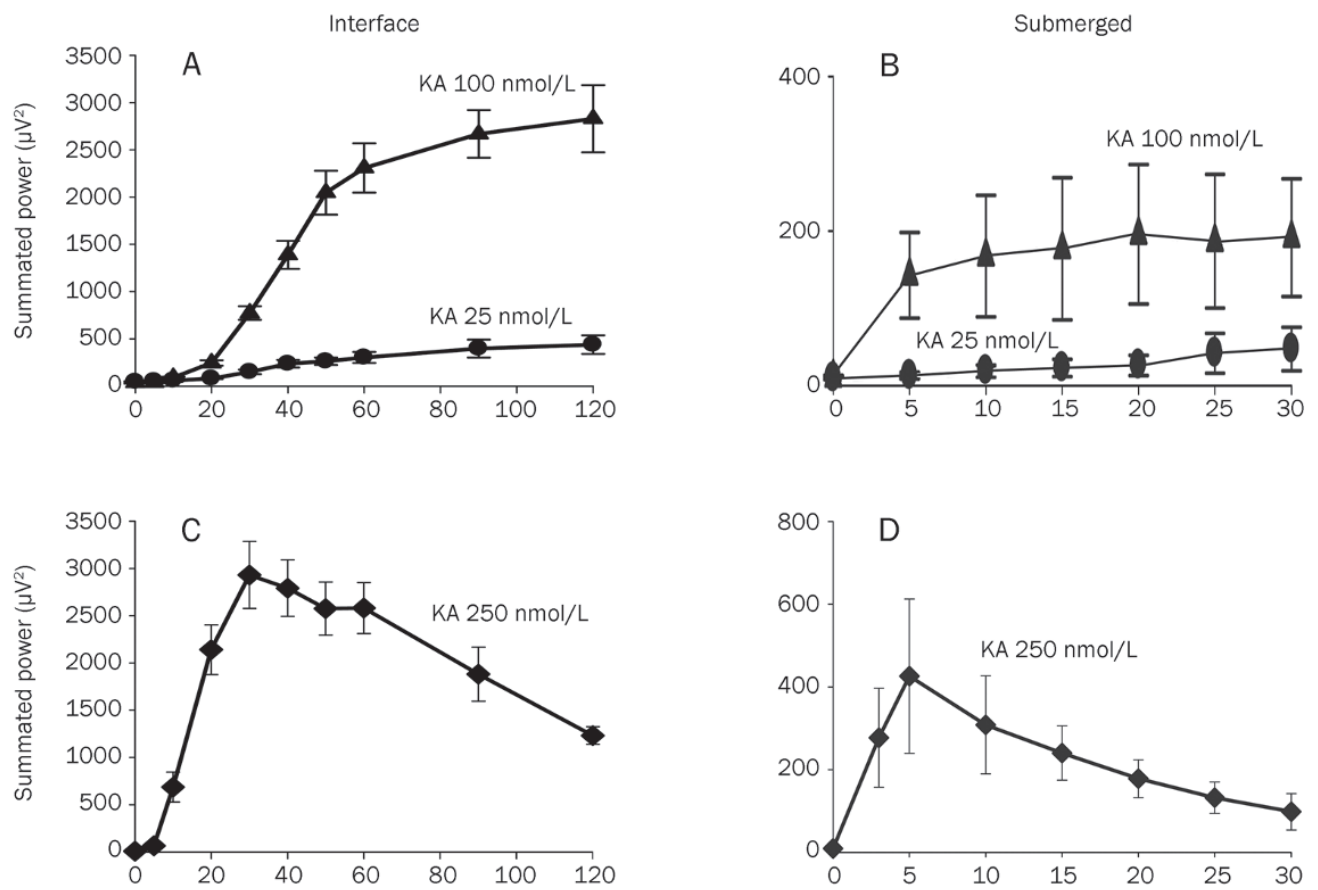

E

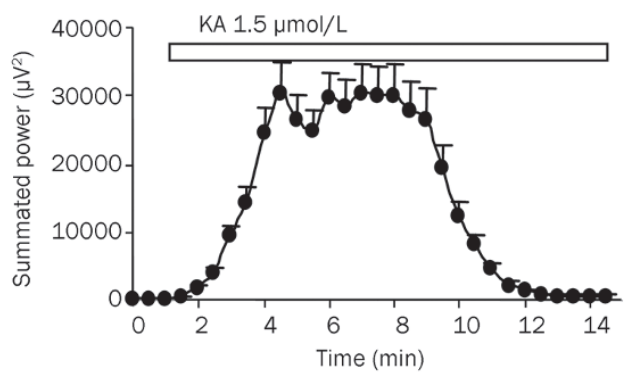

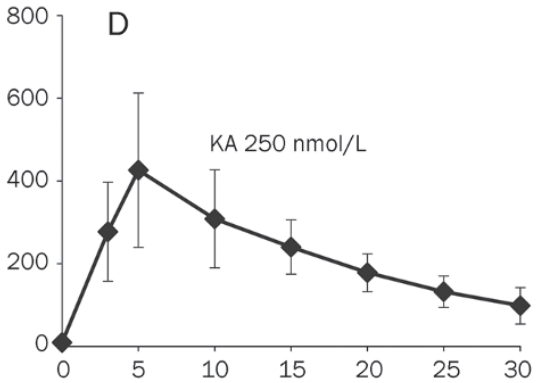

$\mathrm{F}$

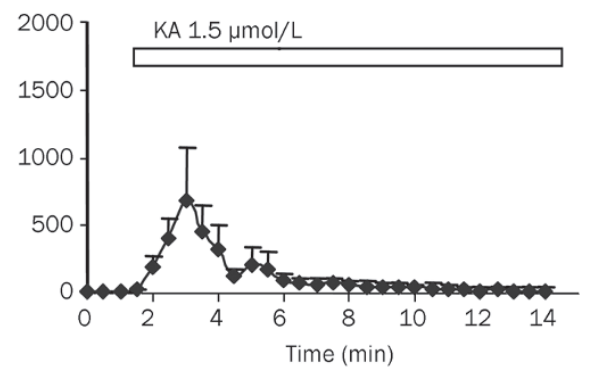

Figure 3. Time-effect curves of summated power at various $K A$ concentrations. Left panel (A, C, E) and right panel $(B, D, F)$ show the summated powers of $\mathrm{y}$ oscillations recorded under interface and submerged conditions, respectively. Larger concentrations of KA (250 $\mathrm{nmol} / \mathrm{L}$ and $1.5 \mu \mathrm{mol} / \mathrm{L}$ ) induced larger amplitude of $\mathrm{y}$ oscillations but reduced temporal stability in both interface (C, E) and submerged slices (D, F). Each data point represents the mean \pm SEM. 
A
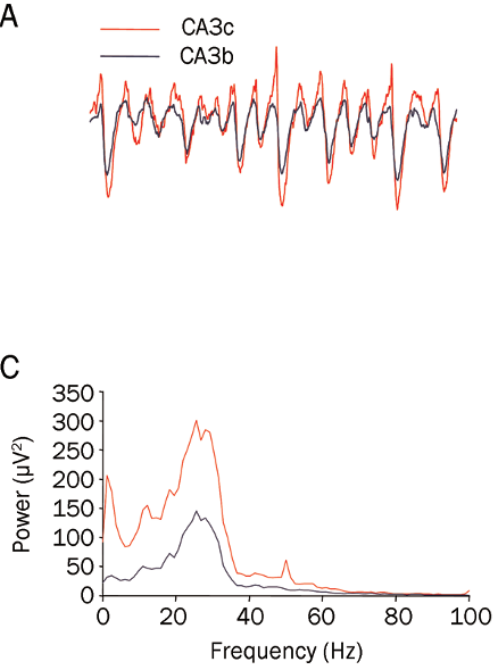

$$
\varlimsup_{100 \mathrm{~ms}} 0.2 \mathrm{mV}
$$

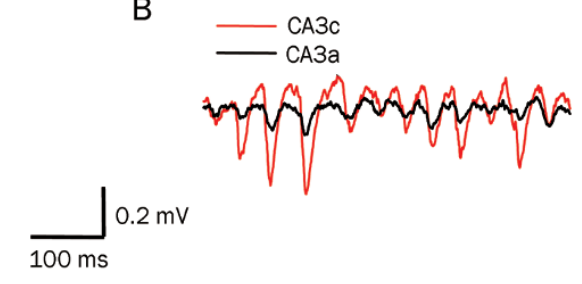

D

B

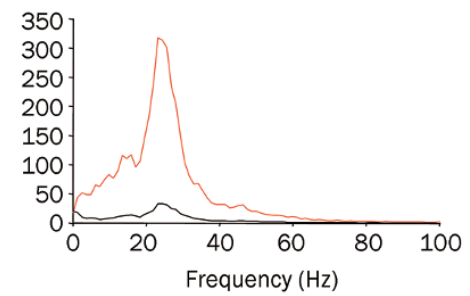

E

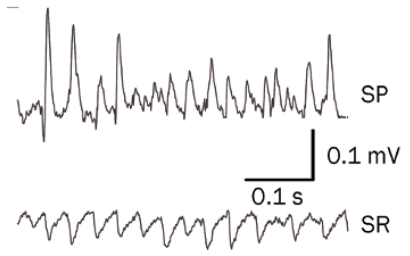

F

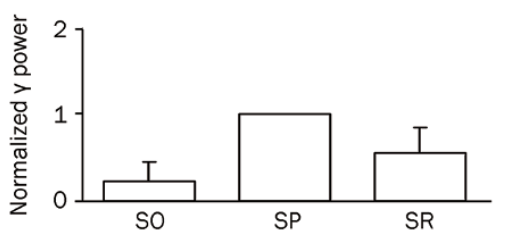

Figure 4. Area and layer specificity of $y$ oscillations. A) Representative recordings of y oscillations from CA3c (red) and CA3b (blue). B) Representative recordings of $\mathrm{y}$ oscillations from CA3c (red) and CA3a (black). C) Power spectra from the recordings of $\mathrm{y}$ oscillations shown in panel A. D) Power spectra from the recordings of $y$ oscillations shown in panel B. E) $y$ oscillations show positivity recorded in SP and negativity recorded in SR. The recording electrode was moved from SO to SP and then to SR and recordings were made at each position. F) Normalized y powers at different layers of hippocampus in CA3c area. For the comparison, summated y power from each location was normalised to the power in SP. Data are given as mean \pm SEM. For interface slices, $n=17$ for the recordings from all the three layers; for submerged slices, $n=13$ for the recordings at SP and SR and $n=5$ for the recordings at so.

\section{Effect of perfusion rate on $y$ oscillations}

The effect of perfusion rate on $\gamma$ oscillations over the range of $1.35-10.5 \mathrm{~mL} / \mathrm{min}$ in both interface and submerged recordings is shown in Figure 5. In the interface recordings, there was no obvious change in the power of $\gamma$ oscillations with increased perfusion rate (line with open circles). In the submerged recordings, increasing the perfusion rate from $1.35-7 \mathrm{~mL} / \mathrm{min}$ increased the power of the $\gamma$ oscillations, whereas the higher perfusion rates $(10.5 \mathrm{~mL} / \mathrm{min})$ reduced the power (line with filled diamonds). The optimal perfusion rate was determined to be $7 \mathrm{~mL} / \mathrm{min}$.

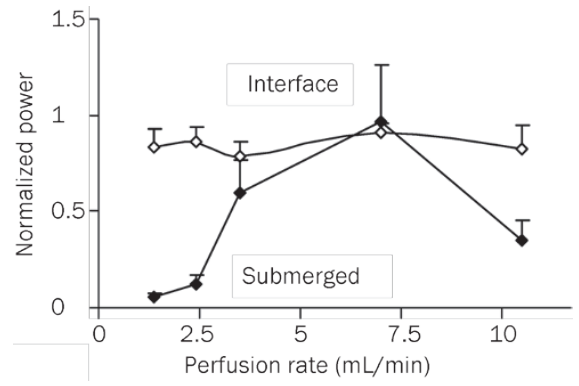

Figure 5. Effect of perfusion rate on y oscillations in interface and submerged slices. Varying the perfusion rate did not alter $y$ oscillation strength in interface slices at 1.35-10.5 mL/min, but affect $y$ oscillation in submerged slices. The optimum perfusion rate for the submerged slices is $5-7 \mathrm{~mL} / \mathrm{min}$. Data are presented as mean \pm SEM. $n=5$ slices

\section{Discussion}

We determined the optimal conditions for the induction of persistent $\gamma$ oscillations in submerged slices. Previous in vitro studies showed that $\gamma$ frequency network oscillations lasting for tens of minutes could be routinely induced in hippocampal slices using an interface-type recording chamber ${ }^{[6,14-16]}$. In contrast, oscillations induced using submerged-type slice chambers, designed for visually guided patch-clamp recordings using infrared DIC optics, lasted only a few seconds and were qualitatively different from those recorded under interface conditions $^{[11,13]}$.

The optimal temperature for $\gamma$ oscillations recorded under submerged conditions is $28-29^{\circ} \mathrm{C}$, a few degrees less than that under the interface conditions $\left(32-33^{\circ} \mathrm{C}\right)$. The reason that a relatively low temperature is required for $\gamma$ oscillations under submerged conditions remains to be determined, but the possibilities include the following situations: 1) because tissues consume less oxygen at lower temperatures, the relatively low temperature may help maintain the $\gamma$ oscillations and 2) the relatively low temperature may help maintain the mitochondrial membrane potential $\left(\Delta \Psi_{\mathrm{m}}\right)^{[17]}$, which is critical for the maintenance of the proton gradient necessary for ATP synthesis in mitochondria. Warming the chamber from 22 to $32{ }^{\circ} \mathrm{C}$ was reported to depolarize the mitochondrial membrane potential and reduce ATP synthesis in cells of the carotid body ${ }^{[17]}$.

The oscillation frequency induced by KA in the submerged slices was at the lower range of the $\gamma$ band. Previous studies have shown that $\gamma$ oscillations typically have a peak frequency of $\sim 35 \mathrm{~Hz}^{[6]}$ under interface conditions. The difference in the peak frequency in this study and those of previous reports may be explained by the temperature at which the experiments were conducted. Our recordings indicate that a $1{ }^{\circ} \mathrm{C}$ 
change in temperature correlates with an alteration of oscillation frequency of $2.3 \mathrm{~Hz}$ (a 9.2\% change per degree). Our results are in line with a previous report in interface slices ${ }^{[18]}$, which showed an $8.3 \%$ reduction in frequency per degree of change in CCh-induced oscillations, and another report in hippocampal slices ${ }^{[19]}$, which showed an $8.8 \%$ reduction per degree in tetanically evoked $\gamma$ oscillations. Temperaturerelated changes in the oscillation frequency are likely associated with changes in inhibitory postsynaptic potential (IPSP) duration. GABAergic IPSP duration is also known to be a key determinant of oscillation frequency ${ }^{[20]}$, and GABAergic IPSPs are prolonged at lower temperatures ${ }^{[18,21]}$. Temperature may also affect excitatory synaptic transmission ${ }^{[22]}$ and contribute to the temperature dependence of oscillation frequency; indeed, gamma oscillation is dependent on both excitatory and inhibitory neurotransmissions.

The oscillation polarity is positive in the SP, where the neuronal somata are located, but negative in the apical dendrites in both interface and submerged slices. The polarity at the soma is positive because GABA, released from presynaptic interneurons, activates GABAA receptors at the postsynaptic membrane of the principle cell, causing $\mathrm{Cl}^{-}$influx and thereby leaving a positive charge outside the soma. The positive potential in the extracellular recordings is caused by a positive charge flowing out of the cell, a process called the "source" in current source density analysis ${ }^{[23,24]}$. Whether the source is an active or passive process depends on the intracellular recording of the soma; if this recording shows a hyperpolarized current (IPSC) coinciding with the source, then the source is likely to be active ${ }^{[25]}$ because hyperpolarization is caused by $\mathrm{Cl}^{-}$influx. In contrast, the negative field potential in the stratum radium (neuronal dendrite location) is due to the positive charge flowing into the dendrite. This process is called a "sink" in current source density analysis. A passive sink is caused by an active source of GABA in the soma, whereas an active sink is caused by the release of glutamate from recurrently excited synapses activating synaptic receptors and causing a positive charge $\left(\mathrm{Na}^{+}\right)$influx. The positive polarity of the KA-induced Y oscillations recorded in the SP in the slices in this study is likely due to active sources ${ }^{[25]}$.

KA-induced $\gamma$ oscillations in the submerged slices in the hippocampal CA3 can be blocked by either NBQX or GABAzine, suggesting that both pyramidal neurons (excitatory) and interneurons (inhibitory) are involved in $\gamma$ oscillations. These oscillations are similar to those recorded in vitro in the entorhinal cortex caused by kainate receptor activation ${ }^{[26]}$, in vitro in the hippocampus caused by cholinergic activation ${ }^{[6,16,27]}$ and in vivo in the hippocampus ${ }^{[5]}$ but are different from the $Y$ oscillations recorded in the CA1 $1^{[14,15,28,29]}$, which showed that both chemically and electrically interconnected interneuronal networks were involved without any contribution from pyramidal cells. The sodium channel blocker, TTX, also largely reduced $\gamma$ oscillations, suggesting that neuronal action potentials (spikes) contribute to the network oscillations ${ }^{[30]}$.

The recovery after a 20-min drug washout showed different dynamics for different blockers: partial recovery for GABA- zine, limited recovery for NBQX and no recovery for TTX. The difference in washout dynamics may be related to the chemical and physical properties of the different drugs. For example, the antagonist NBQX typically cannot be washed out easily due to its lipophilic nature ${ }^{[3]}$. The limited washout time (20 $\mathrm{min}$ ) in this study may have contributed to the limited recovery of these drugs. Under prolonged washout times (up to $1 \mathrm{~h}$ ), there was a dramatic recovery of the $\gamma$ oscillation for the NBQX and TTX treatment groups in some cases.

The development dynamics of KA-induced $\gamma$ oscillation are largely dependent on the concentration of KA. High concentrations of KA (1-2 $\mu \mathrm{mol} / \mathrm{L})$ induced a rapid collapse in $\gamma$ oscillations, suggesting that strong membrane depolarization blocks neurotransmission ${ }^{[32]}$. The micromolar KA-induced rapid collapse of $\gamma$ oscillations may be related to the high demand for ATP in fast network oscillations, causing the neurons to rapidly run out of energy. Therefore, a concentration of KA in the nanomolar range is suitable for the induction of persistent $\gamma$ oscillations.

Under submerged conditions, $y$ oscillation requires a fast perfusion rate $(5-7 \mathrm{~mL} / \mathrm{min})$, indicating the nature of high oxygen demand for fast network oscillations. A high perfusion rate, although providing a rapid exchange of fresh solution, may cause mechanical damage to the brain slice, which likely explains the reduced power of the $\gamma$ oscillations under a high perfusion rate of $10.5 \mathrm{~mL} / \mathrm{min}$ in this study.

In summary, the KA-induced submerged oscillatory activity in the $\gamma$ frequency band in this study is similar to that recorded in the interface recordings with respect to the neurotransmitters and synapses involved but with faster dynamics during development and after the washout. Under submerged conditions, $\gamma$ oscillations can be induced by KA at nanomolar concentrations and at a relatively low temperature. This model will provide neuroscientists, pharmacologists and clinical researchers with a useful tool to study the network mechanisms underlying normal neuronal synchronization and neuronal disorders, such as Alzheimer's disease and schizophrenia, which are known to involve cognitive dysfunction and the impairment of oscillatory activity.

\section{Acknowledgements}

This work was supported by MRC (Medical Research Council) and National Natural Science Foundation of China (Grant № 31070938).

\section{Author contribution}

Lu CB: designed, performed experiments and wrote paper; Wang ZH: performed experiments; Zhou YH: analyzed data; Vreugdenhil M: designed research and wrote paper.

\section{References}

1 Lisman JE, Idiart M. Storage of $7+/-2$ short-term memories in oscillatory subcycles. Science 1995; 267: 1512-5.

2 Jensen 0 , Lisman JE. Novel lists of $7+/-2$ known items can be reliably stored in an oscillatory short-term memory network: interaction with long-term memory. Learn Mem 1996; 3: 257-63. 
3 Herrmann CS, Munk MHJ, Engel AK. Cognitive functions of gammaband activity: memory match and utilization. Trends Cogn Sci 2004; 8: 347-55.

4 Driver JA, Logroscino G, Buring JE, Gaziano JM, Kurth T. A prospective cohort study of cancer incidence following the diagnosis of Parkinson's disease. Cancer Epidemiol Biomarkers Prev 2007; 16: 1260-5.

5 Csicsvari J, Jamieson B, Wise KD, Buzsáki G. Mechanisms of gamma oscillations in the hippocampus of the behaving rat. Neuron 2003; 37: 311-22.

6 Fisahn A, Pike FG, Buhl EH, Paulsen O. Cholinergic induction of network oscillations at $40 \mathrm{~Hz}$ in the hippocampus in vitro. Nature 1998; 394: 186-9.

7 Gloveli T, Dugladze T, Saha S, Monyer H, Heinemann U, Traub RD, et al. Differential involvement of oriens/pyramidale interneurones in hippocampal network oscillations in vitro. J Physiol 2005; 562 : 131-47.

8 Steriade M, Amzica F, Contreras D. Synchronization of fast (30-40 $\mathrm{Hz}$ ) spontaneous cortical rhythms during brain activation. J Neurosci 1996; 16: 392-417.

9 Penttonen M, Kamondi A, Acsady L, Buzsaki G. Gamma frequency oscillation in the hippocampus of the rat: intracellular analysis in vivo. Eur J Neurosci 1998; 10: 718-28.

10 Kann O, Huchzermeyer C, Kovacs R, Wirtz S, Schuelke M. Gamma oscillations in the hippocampus require high complex I gene expression and strong functional performance of mitochondria. Brain 2011; 134: 345-58.

11 McMahon LL, Williams JH, Kauer JA. Functionally distinct groups of interneurons identified during rhythmic carbachol oscillations in hippocampus in vitro. J Neurosci 1998; 18: 5640-51.

12 Kawaguchi Y. Distinct firing patterns of neuronal subtypes in cortical synchronized activities. J Neurosci 2001; 21: 7261-72.

13 Vreugdenhil M, Toescu EC. Age-dependent reduction of gamma oscillations in the mouse hippocampus in vitro. Neuroscience 2005; 132:1151-7.

14 Whittington MA, Traub RD, Jefferys JG. Synchronized oscillations in interneuron networks driven by metabotropic glutamate receptor activation. Nature 1995; 373: 612-5.

15 Boddeke H, Best R, Boeijinga P. Synchronous $20 \mathrm{~Hz}$ rhytmic activity in hippocampal networks induced by activation of metabotropic glutamate receptors in vitro. Neuroscience 1997; 76: 653-8.

16 Palhalmi J, Paulsen O, Freund T, Hajos N. Distinct properties of carbachol-and DHPG-induced network oscillations in hippocampal slices. Neuropharmacology 2004; 47: 381-9.

17 Duchen MR, Biscoe T. Relative mitochondrial membrane potential and $\left[\mathrm{Ca}^{2+}\right]_{\mathrm{i}}$ in type I cells isolated from the rabbit carotid body. J Physiol 1992; 450: 33-61.

18 Dickinson R, Awaiz S, Whittington M, Lieb W, Franks N. The effects of general anaesthetics on carbachol-evoked gamma oscillations in the rat hippocampus in vitro. Neuropharmacology 2003; 44: 864-72.

19 Javedan SP, Fisher RS, Eder HG, Smith K, Wu J. Cooling abolishes neuronal network synchronization in rat hippocampal slices. Epilepsia 2002; 43: 574-80.

20 Traub RD, Whittington MA, Buhl EH, Jefferys JG, Faulkner HJ. On the mechanism of the gamma $\rightarrow$ beta frequency shift in neuronal oscillations induced in rat hippocampal slices by tetanic stimulation. J Neurosci 1999; 19: 1088-105.

21 Banks MI, Li TB, Pearce RA. The synaptic basis of GABAA, slow. J Neurosci 1998; 18: 1305-17.

22 Adelson J, Bhardwaj H, Kannan P. Changes in synaptic delay and EPSP amplitude induced by TEA with 3,4-DAP, temperature and posttetanic potentiation. Pioneering Neurosci 2004; 5: 53-60.

23 Tenke CE, Schroeder CE, Arezzo JC, Vaughan HG. Interpretation of high-resolution current source density profiles: a simulation of sublaminar contributions to the visual evoked potential. Exp Brain Res 1993; 94: 183-92.

24 Martinez DP, Freeman WJ. Periglomerular cell action on mitral cells in olfactory bulb shown by current source density analysis. Brain Res 1984; 308: 223-33.

25 Mann EO, Suckling JM, Hajos N, Greenfield SA, Paulsen O. Perisomatic feedback inhibition underlies cholinergically induced fast network oscillations in the rat hippocampus in vitro. Neuron 2005; 45 : 105-17.

26 Cunningham MO, Davies $\mathrm{CH}$, Buhl EH, Kopell N, Whittington MA. Gamma oscillations induced by kainate receptor activation in the entorhinal cortex in vitro. J Neurosci 2003; 23: 9761-9.

27 Hájos N, Pálhalmi J, Mann EO, Németh B, Paulsen O, Freund TF. Spike timing of distinct types of GABAergic interneuron during hippocampal gamma oscillations in vitro. J Neurosci 2004; 24: 9127-37.

28 Hormuzdi SG, Pais I, LeBeau FE, Towers SK, Rozov A, Buhl EH, et al. Impaired electrical signaling disrupts gamma frequency oscillations in connexin 36-deficient mice. Neuron 2001; 31: 487-95.

29 Traub RD, Whittington MA, Buhl EH, LeBeau FE, Bibbig A, Boyd S, et al. A possible role for gap junctions in generation of very fast EEG oscillations preceding the onset of, and perhaps initiating, seizures. Epilepsia 2001; 42: 153-70.

30 Cunningham MO, Whittington MA, Bibbig A, Roopun A, LeBeau FE, Vogt $A$, et al. A role for fast rhythmic bursting neurons in cortical gamma oscillations in vitro. Proc Natl Acad Sci U S A 2004; 101: 7152-7.

31 Smeraski CA, Dunwiddie TV, Diao L, Finger TE. NMDA and non-NMDA receptors mediate responses in the primary gustatory nucleus in goldfish. Chem Senses 1999; 24: 37-46.

32 Fisahn A. Kainate receptors and rhythmic activity in neuronal networks: hippocampal gamma oscillations as a tool. J Physiol 2005; 562: 65-72. 